\title{
The nexus of economic and institutional evolution is
}

\author{
Bilin Neyapti *, Yavuz Arasil \\ Bilkent University, Dept. of Economics, Bilkent Ankara 06800, Turkey
}

\section{A R T I C L E I N F O}

\section{Article history:}

Accepted 2 October 2015

Available online 21 October 2015

\section{Keywords:}

Institutional evolution

Institutional reform

Economic development

\begin{abstract}
A B S T R A C T
The current state of the development economics literature ascribes an indisputable central role to institutions This paper presents a formal model of institutional evolution that is based on the dynamic interactions between formal and informal institutions and economic development; the main features of the model is consistent with the fundamental theories that shed light to institutional evolution, namely the collective action and transaction cost theories, as well as dialectics. As informal institutional quality accumulates like technological know-how, while the level of formal institutional quality is chosen by the government to maximize welfare, subject to the economic and political costs. The solution of the model yields a punctuated trajectory of formal institutional evolution. Simulations reveal that the extent of diversity in informal institutional quality across a country delays formal institutional reforms. We also observe that, both the optimal quality of formal institutions and welfare are higher the more homogeneous is the country with respect to its informal institutions or the cultural attributes.

(C) 2015 Elsevier B.V. All rights reserved.
\end{abstract}

\section{Introduction}

With the increased contention about the inadequacy of markets alone to deliver economic efficiency, the new institutional economics literature (pioneered by Williamson, 1985, and North, 1990) has gained prominence since the 1990s. The policy counterpart of this has appeared in the Second Washington consensus, coined in the term: "institutions matter". The intertwined nature of the relationship between institutions and economic development has also been the focus of earlier scholars, such as Hayek, Veblen and Marx. While the role of institutions on economic development has been acknowledged widely, the analyses of the role of institutions have been mostly very descriptive, however, as it is also very difficult to decipher as the cause or the effect of economic outcomes in empirical studies. Nonetheless, numerous studies have demonstrated the significant association of the measures of governance and polity with economic performance. Although the channels of association between economic outcomes and institutions have been suggested in political economy, institutional economics and game theory literatures, a unified formal model of institutional evolution vis a vis macroeconomic dynamics has so far been lacking. ${ }^{1}$ This paper presents an original formal model in a step to fill this gap in the literature.

ฟ We thank Cagri Saglam, Jaime Ventura and the participants of the seminars at METU and of the EEFS 2012 conference at Koc University for their valuable comments and suggestions.

* Corresponding author. Tel.: +90 312290 2030; fax: +90 3122665140.

E-mail addresses: neyapti@bilkent.edu.tr (B. Neyapti), avuzarasil@gmail.com (Y. Arasil).

${ }^{1}$ An exception is arguably that of Acemoglu (2006), which however possess several adhoc aspects of evolution and also does not distinguish between the formal and informal institutions whose evolutions are different in important ways.
Economic institutions, formal or informal, are transaction costreducing agents that contribute to economic efficiency by helping agents to reveal preferences, form expectations and internalize externalities. Informal institutions are norms and traditions; they are the unwritten rules of the game and, shape the way economic agents interact in social life or in production processes. Hence, culture encompasses the numerous aspects of informal institutions that evolve slowly albeit continuously with the evolution of elements that are endogenous to a society. Formal institutions, on the other hand, are the written rules and their enforcement characteristics, ranging from constitutions to legislations that regulate the interactions between the government and individuals, and contracts among the private agents. ${ }^{2}$

While formal rules of a society can be changed overnight, the effectiveness of those rules depends on whether they conform to the prevailing informal institutions or not. When in conflict with the prevailing norms and culture, formal rules are usually not adhered to and thus fail to deliver their proposed outcomes. Hence, formal rules cannot be considered as institutions without effective enforcement. Boettke et al. (2008) and Williamson (2009) both argue that informal institutions are more dominant in explaining the development process than formal institutions that need to adapt to the former for their effectiveness. ${ }^{3}$ In a similar vein, Easterly et al. (2006) point at the crucial role of social cohesion in the choice of the level of institutional quality that affects, in turn, economic growth.

\footnotetext{
2 Williamson (2009) defines informal institutions as private constraints and formal institutions as constraints defined and enforced by the government.

${ }^{3}$ Boettke et al. (2008) argue that indigenously introduced endogenous institutions are stickier (more path-dependent) than the exogenously-imposed or guided adoption of institutions.
} 
This paper contributes to the literature of institutional economics by modeling formally the differential patterns of the endogenous evolution of formal and informal institutions in relation with economic development. ${ }^{4}$ We conjecture that the path-dependent pattern of formal institutions gets punctuated when economic inefficiencies lead reform pressures to build up. Such a pattern of institutional change is consistent with the fundamental arguments in the institutional economics literature that can be summarized as follows: i) formal institutional reforms may be costly for at least some part of the society due to the creative destruction that are likely to be generated by those reforms; ii) given continuous economic progress, the persistence or time-dependence of institutions resulting from the status-quo bias leads to inconsistency and conflict within the production processes, and hence pose a deterrent to long-term growth; and iii) a punctuation in the path-dependent pattern indicates that the cost of maintaining the prevailing institutions may eventually exceed the cost of reform. As a result, while economic growth may follow a continuous progress, formal institutions are conjectured to follow a pattern that exhibits intermittent changes, which is consistent with the observed phenomena. ${ }^{5}$

Although the common characteristics of formal institutions, which are called the best-practice with regard to their ability to reduce or eliminate economic inefficiencies, can be freely available information, not all the countries are willing or able to adopt them. From a political economy perspective, Levi (1988) argues that a government who expects a long tenure has an incentive to improve economic institutions. Holcombe and Boudreaux (2013) support this argument with an empirical analysis; they show that the average tenure of an autocrat is positively related with the institutional quality, suggesting that a longtenured autocrat's interests are likely to be aligned with those of the encompassing interests. Olson's collective action theory (1982) argues, however, that special interest groups may get empowered over time in especially stable democracies, and engage in distributional lobbying activities that favor status-quo and thus resist reforms, resulting in institutional sclerosis. Accumulation of such lobbies results in inefficient resource allocation. Similarly, Acemoglu and Robinson (2000) explain the resistance of the politically powerful to institutional development by the potential revenue losses of via creative destruction. Acemoglu and Robinson (2012) refer to the same argument to explain the emergence and persistence of extractive institutions.

Hall and Jones (1999) incorporate institutions as a factor that augments total productivity. This paper considers formal institutions as a specific form of technology. Similar to the regulatory authority that is responsible for technology adoption in Bellettini and Ottaviano (2005) (BO, henceforth), the government in our model chooses the level of formal institutions. ${ }^{6}$ Our model departs from BO in various respects, however. First, we solve a (politically-oriented) government's period by period optimization problem, given that political choices are usually not made with a long-term perspective. We assume that the income levels of economic agents are positively associated with their degree of influence on the decision of institutional reform. ${ }^{7}$ Second, we differentiate between the evolution processes of the formal and informal institutions.

We consider that reforming formal institutions is a form of technological change that may benefit some agents at the expense of others,

\footnotetext{
${ }^{4}$ Neyapti (2013) presents the first formal model that yields a punctuated pattern of institutional change.

${ }^{5}$ Roland (2004) likens such a pattern of institutional change to tectonic pressures building before an earthquake. Earlier studies that utilize the punctuated equilibrium concept (originally developed by biologist Eldredge and Gould, 1972), to explain institutional evolution mostly belong to the political economy literature, and is pioneered by Baumgartner and Jones (1993).

${ }^{6}$ BO explain the process of technology adoption by the differential behavior of the young and the old with regard to innovation and learning by doing.

7 While this formulation of lobbying power for collective action is simplistic, theorizing endogenous coalition formation has been admitted to be rather difficult (see, for example, Grossman and Helpman, 2001).
}

as in creative destruction. Those who benefit from the prevailing institutional network resist the change via political lobbying activities. Since short-tenured governments may tend to accommodate the demands of an organized minority, this may hinder the adaptive changes in formal institutions. ${ }^{8}$ Institutional persistence is punctuated once the costs of maintaining the status-quo exceed the cost of reform. ${ }^{9}$

The literature on institutional evolution ranges from the adaptive approach of North (1990) to the historical and path-dependence approaches, exemplified by Kuran (2004), and the political-economy approach of Acemoglu (2006). Acemoglu proposes a framework of institutional change where the society is composed of three classes: the workers, the middle-class and the elite. Both the elite and the middle class invest, but their productivities differ. Inefficiencies arise in the form of the elite's rent extraction and/or property rights enforcement, or preventing the technology adoption by the middle class. The probability of a political power shift (from, elite to the middle class) develops as the middle class incomes rise. The change of institutions is explained by the middle class ending the domination of the elite with some exogenous probability. Institutions are hence modeled by Acemoglu primarily as the agents of income distribution, rather than being determined by it. ${ }^{10}$ Other formal models of institutional evolution usually utilize a game-theoretic framework. Desierto (2005) models the evolution of institutional and technological change together, albeit without any consideration of interest groups. Yao (2004) models institutional change in relation to the welfare distribution. These two studies, however, do not differentiate between the evolution of formal and informal institutions. Given that a game itself imposes a built-in institutional structure, this paper does not adopt a game-theoretic approach. ${ }^{11}$

Hence, this paper differs from the existing literature in several aspects. First, it extends the framework of Neyapti (2013) by modeling explicitly the interactions between the formal and informal institutions, on the one hand, and each of their relation with the economic development process, on the other. ${ }^{12}$ Second, we model explicitly the cost of inefficiency that arises from the inconsistencies between the two types of institutions. ${ }^{13}$ In order to model the interest group dynamics, we consider, for simplicity, two economic sectors or social groups that are distinguished by the initial levels of their capital and informal institutional development. The differential developments of two groups' informal institutions identify their business culture or the way these groups conduct business, which, combined with different levels of physical capital, account for the differences in their modes of production. ${ }^{14}$ The differences in the mode of production across the sectors thus imply different preferences, underlying the diverse demands for formal institutions. By contrast, the supply of formal (economic) institutions, which constitute the legal aspects of production relations, is common to the economy. Formal institutions are chosen by the government to

\footnotetext{
${ }^{8}$ Adaptive change means that institutions evolve to eliminate new transaction costs that emerge as economies develop.

9 Based on Arthur (1988), North (1990) argues that institutional inefficiencies arise due to multiple equilibria; bad luck in persistence of an efficient technology; lock-in; and pathdependence.

${ }^{10}$ Acemoglu distinguishes between the political and economic institutions, the former of which determines de-jure and the latter represents de-facto political power.

${ }^{11}$ As Aoki (2007) argues, institutions are "not summary representations of exogenous data of the game such as technology and preferences, but a summary representation (rules cum beliefs) regarding how the game is being played".

12 The taxonomy of formal and informal institutions studied here does not coincide with that of political and economic institutions in Acemoglu (2006). We conjecture that formal institutions that are once supported by powerful interest groups may eventually pose a political constraint for their own actions due to the dynamics of the economics and interest groups. This highlights the importance of taking into account the evolution of informal institutions as distinct from that of formal institutions. Mathers and Williamson (2011), Williamson and Mathers (2011) and Williamson and Kerekes (2011) also emphasize the distinction between formal and informal institutions.

${ }^{13}$ Kane (1988) provides a thorough discussion of a similar dialectical process in the context of financial regulation.

${ }^{14}$ The term mode of production, as in historical materialism, stands for the combination of production relations and factors of production.
} 
maximize welfare, although this choice might be affected disproportionately by the powerful interest groups that have privileged access to resources. ${ }^{15}$ Differential growth patterns of the two groups' informal institutions, may however lead to shifts in the size of their relative incomes and thus relative political powers over time, which in turn could affect the path of institutional changes. ${ }^{16}$

The main implication of the current model is that, ceteris paribus, the highest levels of welfare and formal institutional quality are accompanied by homogeneity in informal institutions across the society. The current framework highlights the important role of the level and heterogeneity of informal aspects of production relations on economic development; socio-economic and cultural homogeneity spurs growth via effective institutional reform. The finding of the paper shed light on why convergence occurs between countries that have similar norms. They also conform to the studies that demonstrate the negative effects of social and political heterogeneity on economic development (see, for example, Horowitz, 1985; Montalvo and Reynal-Querol, 2005). The remainder of the paper is organized as follows. Section 2 describes the model and provides the implications. Section 3 concludes.

\section{The model}

Consider an economy that consists of two sectors, or regions, denoted by $j(j=1,2)$, the first of which is less capital-intensive than the second. ${ }^{17}$ For purposes of simplicity, we rule out migration and spillovers between these sectors. The production function of sector $j$ is given by:

$y^{j}=A^{j}\left(F, N^{j}\right) f\left(k^{j}\right)$, where $f^{\prime}>0$ and $f^{\prime \prime}<0$

where $y^{j}$ is the level of output and $k^{j}$ is the sector-specific level of capital (physical and/or human) per-capita in sector $j$, and $f$ is a function that is assumed to exhibit diminishing returns. Out key assumption is that the level of technology in sector $j\left(A^{j}\right)$ is determined by the quality of production relations determined by $F$ and $N^{j}$ that stand for the formal and informal quality of institutions, respectively.$^{18} \mathrm{~F}$ represents the formal quality of organizational structure, which are the legislation or written contracts; and $N^{j}$ represents the quality of the operational characteristics of the production relations that are determined by the web of norms in that sector. ${ }^{19}$ Since developments in physical capital necessitate appropriately skilled labor to work with it, physical and human capitals are complementary to each other. ${ }^{20}$ We further assume that the

\footnotetext{
${ }^{15}$ In Neyapti (2013), the political economy aspect of institutional evolution is implicit in the cost function of formal institutional change.

16 See Neyapti (2013) for some quantified examples of formal institutional changes that exhibit a punctuated pattern. Several advanced economies also offer recent evidence of conflict in their production relations in the form of formal institutional reforms not catching up with the level of economic sophistication. The slow progress with regard to fiscal reforms in the European Union and that with regard to the financial regulatory reforms in Japan and the US are cases in point. The great recession has also revealed the inconsistency between the state of financial progress and the institutional mechanisms that are supposed to deal with their externalities, among other institutional deficiencies.

17 The sectors can be identified as modern versus traditional; or tradable versus nontradable. In a global context, one may also consider the divide as the North and the South, indicating different $N$ 's but a level of $F$ being either internationally proposed by a global authority or conceived as the best-practice.

18 The quality of both $F$ and $N^{j}$ is measurable on a cardinal scale, where increasing numbers reflect increased ability to reduce transaction costs.

19 See Granville and Leonard (2010), for example, for empirical evidence on the endogeneity of technology to informal institutions in Russia.

20 An example in point is in regard to the invention of Kodak camera, which led people to realize the importance of protecting their privacy against "Kodaking" (being taken a picture of without permission) that led to the legal right to privacy. The story shows how norms followed technology, which was then followed by a legal adjustment. Another example can be found in Danielson et al. (2009) in the context of biotechnology and changing societal norms. The FDI literature also presents arguments supportive of the norms changing with capital accumulation: FDI flows are often accompanied by intense training in the host country; they are hence argued to result in technological as well as organizational diffusion.
}

evolution of $N^{j}$ depends on $k^{j}$, as in the process of technological know-how, or embodied technological change. Thus, the accumulation process of $N^{j}$ is given by:

$N_{t}^{j}=N_{t-1}^{j}+g\left(k_{t}^{j}\right)$, where $g^{\prime}\left(k_{t}^{j}\right)>0$ and $g^{\prime \prime}\left(k_{t}^{j}\right)<0$.

Hence, the sectors, or the regions, of the economy differ with respect to their social and physical capital stocks: $N^{j}$ and $k^{j}$, respectively, in addition to the saving rates as will be shown below. For analytical simplicity and tractability, we avoid additional forms of heterogeneity and assume that the same type of product is produced in both sectors and that there is no exchange between the sectors; hence the price is fixed and normalized to one. ${ }^{21}$

A representative household in each sector consumes and saves (invests) its disposable income. Hence, the market clearing condition for sector $j$ is given by:

$c_{t}^{j}+i_{t}^{j}+\psi\left(\Delta F_{t}, F_{t-1} / N_{t}^{j}, y_{t}^{j}\right)=y_{t}^{j}$

where $c$ and $i$ stands for consumption and investment (or savings), respectively. Given the investment for group $j$ :

$i_{t}^{j}=s^{j} y_{t}^{j}$

The capital stock of sector $j$ accumulates as:

$k_{t+1}^{j}=(1-\delta) k_{t}^{j}+i_{t}^{j}$.

The function $\psi$ represents the cost of institutional reform that is paid by sector $j$ proportional to each sector's income level. The cost depends on both the magnitude of change in the level of formal institutions and the extent of inconsistency between formal and informal institutions, given by the term $\left(F_{t} / N_{t}^{j}\right)$. More explicitly, the cost function for sector (or regions) $j$ is:

$$
\begin{aligned}
\psi^{j}\left(\Delta F ; F_{t} / N_{t}^{j} ; y_{t}^{j}\right)= & \gamma_{1}\left[\left(F_{t}-F_{t-1}\right)\right] y_{t}^{j} \\
& +\gamma_{2}\left(1-\frac{F_{t-1}}{N_{t}^{j}}\right) y_{t}^{j} \quad ; \text { where } 0<\gamma_{1,2}<1
\end{aligned}
$$

The first term of Eq. (4) stands for the administrative cost of changing $F$ that accrues to sector $j$, as a tax on its income. Tax revenues are then used by the government for the purpose of financing the institutional reform. ${ }^{22}$ The second term of the expression stands for the extent of economic inefficiency, measured as a portion of income in sector $j$, arising from an inconsistency between $F$ and $N^{j}$; increasing the ratio $\left(F_{t-1} / N_{t}^{j}\right)$ implies increasing consistency in the institutional network of sector $j$ (assuming that the formal institutions in a framework of endogenous institutional reform are likely to be bounded from above by the existing norms). ${ }^{23}$ Given $F$, this ratio continues to fall as $N^{j}$ increases with capital accumulation, which implies increasing inconsistency between the two types of institutions and hence increasing inefficiency in the mode of production. The second part of the cost function can be interpreted as the welfare loss of group $j$ from operating with the existing level of formal institutional quality. Adverse selection and

\footnotetext{
21 This assumption is necessitated, given the level of the complexity of the dynamics involved in the model. Since the focus of the model is to generate differential demands for institutional reform, which we achieve by introducing different initial level and progress of technological development, additional complication via exchange across sectors is avoided to keep the model parsimonious.

22 The government sector is not explicitly modeled here; the only role of the government is to tax in order to finance the institutional change. Hence, $\mid G=T_{t}=\gamma_{1}\left[\left(F_{t}-F_{t-1}\right)\right] \sum y_{t}^{j}$ where the right hand side denotes the total administrative cost of changing $F$.

${ }^{23}$ In a similar fashion, though without making a distinction between formal and informal institutions, Desierto (2005) considers the homogeneity of institutional infrastructure or environmental proximity in modeling technological evolution.
} 
moral hazard risks increase as the existing institutional mechanisms fail to cope with the new types of transaction costs that emerge as the economic activity gets more advanced. If formal and informal institutions are entirely consistent with each other, the cost becomes zero and welfare loss is nil. So long as $\left(F_{t-1} / N_{t}^{j}\right)<1$, however, the inefficiency arising from maintaining $F$ (the status-quo bias) is weighted by the optimizer against the cost of reforming $F$ (the first term); the reform takes place if the former cost is more than the latter.

Combining Eqs. (3), (4) and (6), the consumption function can be written as:

$c_{t}^{j}=\left(1-s^{j}-\gamma_{1} \cdot\left[\left(F_{t}-F_{t-1}\right)\right]-\gamma_{2}\left[1-\frac{F_{t}}{N_{t}^{j}}\right]\right) \cdot y_{t}^{j}$.

\subsection{The government's problem}

The government chooses $F_{t}$ in order to maximize the sum of local utilities over a given incumbency period. Such short-sighted government behavior can be justified for the case of democratic countries where governments face a positive probability of losing the elections at the end of each period. Accordingly, the objective function of the government is:

$$
\underset{F t}{\operatorname{Max}} U^{G}=u\left(c_{t}^{1}\right)+u\left(c_{t}^{2}\right)
$$

where each group, or sector/region, $j(j=1,2)$ is assumed to have logarithmic utility:

$u\left(c_{t}^{j}\right)=\ln \left(c_{t}^{j}\right)$

We assume that the per capita income of each group is of a CobbDouglas form. Hence, Eq. (1) is rewritten as:

$y_{t}^{j}=\left(F_{t-1} \cdot N_{t-1}^{j}\right)^{\theta}\left(k_{t-1}^{j}\right)^{\alpha}$

where $\theta$ measures the contribution of technology to income, and $\alpha$ represent the income share of capital, respectively, where we assume that the condition: $2 \theta+\alpha=1$ holds to ensure constant returns to scale. Substituting Eq. (1') into Eq. (7), the utility function of group $j$ (Eq. (9)) becomes:

$u\left(c_{t}^{j}\right)=\ln \left(\left(F_{t-1} \cdot N_{t-1}^{j}\right)^{\theta} \cdot\left(k_{t-1}^{j}\right)^{\alpha} \cdot\left(1-s-\gamma_{1} \cdot\left[F_{t}-F_{t-1}\right]-\gamma_{2} \cdot\left[1-\frac{F_{t-1}}{N_{t}^{j}}\right]\right)\right)$

where $k^{j}$ is given in Eq. (5) and the evolution of the informal institution, $N^{j}$, is given explicitly as:

$N_{t}^{j}=N_{t-1}^{j}+b^{j} \log \left(k_{t}^{j}\right)$

where $b^{j}\left(0<b^{j}<1\right)$ stands for the speed of learning by doing in sector $j$. Hence, the government's problem (Eq. (8)) becomes:

$$
\begin{gathered}
\max _{F_{t}} \ln \left(\left(F_{t-1} N_{t-1}^{1}\right)^{\theta}\left(k_{t-1}^{1}\right)^{\alpha}\left(1-s_{1}-\gamma_{1}\left[F_{t}-F_{t-1}\right]-\gamma_{2}\left[1-\frac{F_{t-1}}{N_{t}^{1}}\right]\right)\right) \\
+\ln \left(\left(F_{t-1} N_{t-1}^{2}\right)^{\theta}\left(k_{t-1}^{2}\right)^{\alpha}\left(1-s_{2}-\gamma_{1}\left[F_{t}-F_{t-1}\right]-\gamma_{2}\left[1-\frac{F_{t-1}}{N_{t}^{2}}\right]\right)\right) .
\end{gathered}
$$

Eq. (11) is solved subject to Eq. (2'). Assigning equal weights to the utilities of the two income groups, which are differentiated on the basis of their $N, k$ and $y$, amounts to assigning a greater weight to the group with relatively higher income (per representative household). Because the economic power usually determines the political power, we consider that the preference of the economically dominant sector plays a dominant role in the decision of the government that cares about its re-electability. ${ }^{24}$ The optimization is performed given the following admissibility constraints:

$c_{t}^{j}>0 ; \quad$ and $\quad F_{t} \geq F_{t-1}$,

where the second constraint indicates that the institutional reform is made only to increase the quality of formal institutions; we call this the irreversibility condition.

The dynamics of the model can be summarized as follows: $N$ evolves with the contemporaneous value of $k$ (Eq. (2')), whose accumulation depends on the past value of $F$ (due to Eqs. (1'), (5) and (6)); the choice of $F$ depends on the contemporaneous level of $N$, which together with $F$, determines $y$ (Eq. ( $\left.1^{\prime}\right)$ ) in the next period.

The maximization problem outlined in Appendix 1 yields the dynamic expression (Eq. (15)). We use the MATLAB software to solve this expression for the optimum $F_{t}\left(F_{t}^{*}\right)$. The solution of $F_{t}^{*}$ involves two roots, although only one of these roots satisfies the admissibility constraints reported above. ${ }^{25}$ We perform a simulation analysis to obtain the evolution trajectory of $F_{t}^{*}$ and its relation with the rest of the model parameters are obtained from the comparative statics that are obtained as closed-form equations.

Table 1 summarizes the feasible ranges of parameter values we use to simulate the optimum solution of the model.

The simulation process is summarized as follows.

i) From the set of feasible values of the model parameters $(\beta, \theta, \delta$, $\alpha^{j}, b^{j}, s^{j}, \gamma_{1}$ and $\left.\gamma_{2}\right)$, cross-combinations are selected incrementally, along with the (pre-determined) initial $(t-1)$ values of $k_{t}^{j}, N_{t}^{j}$ and $F$.

ii) The non-depreciated portion of initial capital $\left((1-\delta) k_{t-1}^{j}\right)$, the saving rate $\left(s^{j}\right)$ and the initial income level $\left(y_{t-1}^{j}\right)$ determines the level of $k_{t}^{j}$ in each period $t$ (using Eqs. (4) and (5)).

iii) Given $N_{t-1}^{j}$ and $k_{t}^{j}, N_{t}^{j}$ is determined via Eq. (2).

iv) Given $k_{t}^{j}, N_{t}^{j}$ and their initial values, the government chooses $F_{t}$ to maximize the weighted total utility of consumers; that is, Eq. (15) is solved for $F_{t}$.

v) If $F_{t}$ satisfies the admissibility conditions, $y_{t+1}^{j}$ is determined based on $k_{t}^{j}, N_{t}^{j}$ and optimal $F_{t}$ via Eq. (1'). (If not, the loop goes back to step $i$ ).

vi) The next period values are determined as the loop continues with step $i i$, taking the previous set of simulations as the initial values.

The simulations yield 784,000 data points that allow us to report several remarks with reasonable conviction. The following section summarizes the results of the simulation analysis.

\subsection{Simulation analysis}

Given the initial values of $\left\{F, k^{1}, k^{2}, N^{1}, N^{2}\right\}$, where $k_{0}^{1}<k_{0}^{1}$ and $N_{0}^{1}<N_{0}^{2}$ and hence $y_{0}^{1}<y_{0}^{226}$ the optimum trajectories for the two sectors can further be differentiated on the basis of $b^{j}{ }^{j}$ s. It is possible that $b^{j}$ is higher for the backward region than the other, reflecting either the desire of the former to catch up with the developed region or the convergence factor. As a result, $N^{1}$ may grow faster than $N^{2}$ and hence $y^{1}$ may catch

\footnotetext{
${ }^{24}$ Given the level of the complexity of the current model, we refrain from introducing political factors that could be consider in addition to the economic differences between the groups. This feature is to be studied in a separate paper.

25 Both the roots are too long to report here, but available from the author upon request.

${ }^{26}$ The sample of initial values that are used in the simulation analysis are reported in Appendices 2 and 3. Alternative set of trajectories based on of different initial values, which we do not include in the paper in the interest of space, can be provided upon request. We note below, however, some of the general observations based in the results of the changes in the initial values.
} 
Table 1

Calibration of the model parameters (for $j=1,2$ ).

\begin{tabular}{lll}
\hline & $\begin{array}{l}\in \text { [the } \\
\text { interval }]\end{array}$ & Description \\
\hline$\delta$ & 0.1 & Rate of depreciation \\
$\theta$ & {$[0.1,1.0]$} & $\begin{array}{l}\text { Contribution of technology to output } \\
\text { Cost of changing institutions }\left(\gamma_{1}\right) ; \text { the economic cost } \\
\text { of existing institutional inconsistency }\left(\gamma_{2}\right)\end{array}$ \\
$\gamma_{i}(i=1,2)$ & {$[0.01-1.0]$} & $\begin{array}{l}\text { Share of capital in sector } j \text { 's income } \\
\alpha^{j}\end{array}$ \\
$b^{j}$ & {$[0.1-0.5]$} & Rate of learning in sector $j$ \\
$s^{j}$ & {$[0.1-1]$} & Rate of saving in sector $j$ \\
\hline
\end{tabular}

Assumption for the CRTS technology $\left(2 \theta+\alpha_{j}\right)=1$.

up with $y^{2}$. This feature of the model is crucial for the possibility of economic or political power switch, and thus the utility weights in the optimization problem, between the two groups. ${ }^{27}$

Given the set of parameter ranges provided in Table 1 and a set of initial values, Appendix 2 provides a sample of trajectories obtained for $F^{*}, y^{1}, y^{2}, N^{1}$ and $N^{2}$. The simulations exhibit a punctuated pattern of change in $F^{*}$, corresponding to the relatively smoother transitions in $y^{j}$ s and $N^{j}$ s. Next, we investigate the effects of the alternative sets of initial values. Ceteris paribus, we observe that an increase in the initial value of $N^{1}$, that is, smaller $\left(N^{1} / N^{2}\right)$, leads to a faster and greater reform in $F$. In addition, we observe that the initial values of $F$ do not play a major role for the eventual values of $F^{*}$ or the $y^{j}$ s that are attained. We also observe, however, that $F$ changes faster the higher are learning and the saving rates. The latter observation implies that, ceteris paribus, countries may eventually convergence towards similar levels of formal institutional quality; but, conditional, rather than absolute, convergence takes place and such convergence may not be accompanied by a domestic convergence in the income levels.

Remark 1. Culturally more homogenous countries can reform formal institutions more and faster.

Remark 2. Regardless of the income and cultural differences, optimal levels of $F$ increases with improved learning by doing.

The exercise also shows that various scenarios (not shown) are possible regarding income trajectories; for example, the $y^{j^{j}}$ s may converge while $N^{j}$ 's trajectories may cross-over each other, depending on the initial values and alternative parameter combinations. ${ }^{28}$ Examples to the pattern of formal institutional change indicated by the current model can be found in several empirical analyses, such as the legal indices of central bank independence of Cukierman et al. (1992, 2002); the index of bank regulation and supervision quality of Neyapti and Dincer (2005); and polity index of Marshall et al. (2011). ${ }^{29}$

We next perform simulations performed over all the feasible parameter ranges of the model, which reveal additional interesting observations. We report below those results that are robust to the changes in initial values of the variables. First, the comparative statics analysis, based on the partial derivatives of the expression for $F^{*}$, reveals that $F_{t}^{*}$ is positively related with $\theta$, whereas it is negatively related with $s^{j}$, $N^{j}, y^{j}$ and $\gamma_{1}$. These are all expected signs, where the negative relationship with $s^{j}, N^{j}$ and $y^{j}$ indicates the substitution effect. The effect of $\gamma_{2}$ on $F$, however, is not definitive; ceteris paribus, the increasing cost of

\footnotetext{
27 Williamson (2009) provides a comparative study of the status of $F$ and $N$ in a sample of countries, noting that in the majority of developed countries $F$ lags behind $N$, whereas the reverse holds in most of the developing countries. The current framework allows for both cases as the findings of the analysis remain robust across them.

${ }^{28}$ In the interest of space, we provide only one of these calibration results in Appendix 2; further simulations are available from the author upon request.

${ }^{29}$ Graphical representation of the evolution trajectories these institutional attributes are reported in Neyapti (2013).
}

economic inefficiency arising from maintaining formal institutions that are inconsistent with the informal quality of institutions may or may not lead to formal institutional reform, depending on the rest of the parameters and initial values.

The simulation methodology also allows us to investigate the relationship of formal institutional quality with income distribution $\left(y^{1} / y^{2}\right)$ and cultural heterogeneity, the latter of which we measure by the divergence between the informal institutions across the regions $\left(N^{1} / N^{2}\right)$. Cultural homogeneity implies the networking intensity in the society, or the value of social capital; while the lack of it implies the lack of trust and thus increased transaction costs in production relation. The most interesting findings of this paper emerges to be the positive relationship between $F^{*}$ and $\left(N^{1} / N^{2}\right)$. Given the positive relationship between $F^{*}$ and welfare, we also observe that $\left(N^{1} / N^{2}\right)$ and welfare are positively related. More interestingly, as the relationship between $\left(N^{1} / N^{2}\right)$ and $F^{*}$ appears to exhibits an inverse-bell shape, the upper end of the $\mathrm{F}^{*}$ values are associated with $\left(N^{1} / N^{2}\right)$ values close to one. Appendix 3 (Figs. A3.1 and A3.2) presents these results graphically based on the simulation data. ${ }^{30}$

Remark 3. The highest feasible levels of optimal formal institutional quality and welfare are associated with high cultural homogeneity.

We note also, however, that as $\left(N^{1} / N^{2}\right)$ increases, the response of $F^{*}$ to the economic cost of inconsistency between $F$ and $N\left(\partial F^{*} / \partial \gamma_{2}\right)$ turns definitely negative, which indicates that high levels of cultural homogeneity is associated with greater resistance to formal institutional reform (or to creative destruction) (see Appendix Fig. A3.3).

Remark 4. High levels of cultural homogeneity may be associated with stronger status-quo bias or resistance to creative destruction.

It is interesting to note that, ceteris paribus, the effects of neither the relative savings rates $\left(s^{1} / s^{2}\right)$ nor the relative learning rates $\left(b^{1} / b^{2}\right)$ alone play a clear role on the level of $F^{*}$, because a lower value of each of these variables can be compensated for by another parameter.

\section{Concluding remarks}

This paper presents a formal model of the dynamic interrelationships between the formal and informal institutions, on one hand, and between those and the economic growth process, on the other. Facing some degree of heterogeneity in initial incomes, as well as the economic and political costs of reforming formal institutions, the politicallymotivated government, solves for the optimum level of formal institutional quality.

The optimal trajectory of formal institutions implied by a politically motivated decision making is consistent with the observed punctuated pattern of formal institutional change. This pattern reflects the pathdependence in institutions due to the status-quo bias and, as implied by Olson's concept of institutional sclerosis, the resistance of the politically powerful to efficient institutional change or creative destruction, only to be punctuated when the calculus of consent dictates the inevitable threshold for a change. Simulations reveal that the higher rate of learning by doing in the relatively less capital-intensive, or the poorer, sector of the economy is essential for closing the income gap within a country - regardless of the initial level of formal institutions. Simulations also show that greater heterogeneity across sectors leads to further delayed reforms. By the same token, differential rates of saving that, ceteris paribus, lead to growing socio-economic differentials limit economic growth by causing delays in reforming formal institutions.

\footnotetext{
30 Using some proxies, one can support these findings empirically by, say, the negative association of ethnic polarization and governance (available from the author upon request).
} 
Hence, a consensus for reform that spurs economic growth in developing countries appears to necessitate social cohesion, which is consistent with the evidence (see, for example, Easterly et al., 2006). The simulations of the model imply the importance of cultural homogeneity for institutional and welfare improvement. On the other hand, at high levels of formal institutional quality, cultural homogeneity may pose a deterrent to further reforms due to strong status-quo bias.

Besides analyzing the national development processes, the current model can be utilized to understand the convergence around the world based on the diffusion of the best-practice institutions. Many de- veloping countries possess a highly heterogeneous structure of norms and income levels or dual economies. Accordingly, as many developing countries lag in adopting and implementing improved institutional mechanisms, the effective institutional convergence has been slow. The evidence in this paper suggests that making convergence to high income levels a realistic goal requires the development of the local and national institutions in a holistic fashion, notwithstanding the idiosyncratic characteristics of the different regions. Investing in arts and education thus appears to be the key step to succeed the convergence of informal institutions via spreading trust and business ethic.

\section{Appendix 1. Temporary optimization of $F\left(F_{t}{ }^{*}\right)$}

We utilize the following identity in order to simplify the solution of the problem:

$$
\ln \left(c_{t}^{1}\right)+\cdot \ln \left(c_{t}^{2}\right)=\ln \left[\left(c_{t}^{1}\right) \cdot\left(c_{t}^{2}\right)\right]
$$

where the term $\left(c_{t}^{1}\right)^{1 / 2} \cdot\left(c_{t}^{2}\right)^{1 / 2}$ is expressed as:

$$
\begin{aligned}
& \left(c_{t}^{1} \cdot c_{t}^{2}\right)=\underbrace{\left(N_{t}^{1}\right)^{\theta} \cdot\left(N_{t}^{2}\right)^{\theta} \cdot\left(k_{t}^{1}\right)^{\alpha} \cdot\left(k_{t}^{2}\right)^{\alpha}}_{x_{1}} \\
& \left(F_{t}\right)^{\theta} \underbrace{\left(1-s_{1}-\gamma_{1}\left[F_{t}-F_{t-1}\right]-\gamma_{2}\left[1-\frac{F_{t}}{N_{t}^{1}}\right]\right) \cdot\left(1-s_{2}-\gamma_{1}\left[F_{t}-F_{t-1}\right]-\gamma_{2}\left[1-\frac{F_{t}}{N_{t}^{2}}\right]\right)}_{x_{2}}
\end{aligned}
$$

Since the components of $x_{1}$ are determined at time $t-1$ and does not include the term $F_{t}$, the optimal $F_{t}$ which is denoted by $F^{*}$ can be defined as:

$$
F^{*}=\arg \max \left\{\ln \left(x_{1}\right)+\ln \left(x_{2}\right)\right\}=\arg \max \left\{\ln \left(x_{2}\right)\right\} .
$$

Hence, from Eqs. (14) and (15), $F^{*}$ maximizes the following expression:

$$
\ln \left(1-s_{1}-\gamma_{1} \cdot\left[F_{t}-F_{t-1}\right]-\gamma_{2} \cdot\left[1-\frac{F_{t}}{N_{t}^{1}}\right]\right)+\ln \left(1-s_{2}-\gamma_{1} \cdot\left[F_{t}-F_{t-1}\right]-\gamma_{2} \cdot\left[1-\frac{F_{t}}{N_{t}^{2}}\right]\right)+\theta \cdot \ln \left(F_{t}\right)
$$

The first order condition with respect to $F_{t}$ yields the following expression:

$$
\left[\frac{\left(\gamma_{1}-\frac{\gamma_{2}}{N_{t}^{1}}\right)}{\left(1-s_{1}-\gamma_{1} \cdot\left[F_{t}-F_{t-1}\right]-\gamma_{2} \cdot\left[1-\frac{F_{t}}{N_{t}^{1}}\right]\right)}\right]+\left[\frac{\left(\gamma_{1}-\frac{\gamma_{2}}{N_{t}^{2}}\right)}{\left(1-s_{2}-\gamma_{1} \cdot\left[F_{t}-F_{t-1}\right]-\gamma_{2} \cdot\left[1-\frac{F_{t}}{N_{t}^{2}}\right]\right)}\right]=\frac{\theta}{F_{t}}
$$

The second derivative test proves that the solution of the above equation is a local maximizer. 
Appendix 2. Sample trajectories of $F^{*} N^{j}$ and $y^{j}\left(\right.$ for $\alpha^{2}=0.3 ; s^{2}=0.2 ; b^{2}=0.5$; and $\theta=0.3$ and the initial values: $\left\{k^{1}, k^{2}, N^{1}, N^{2}, F\right\}=\{10$, $50,20,60,10\}$ )
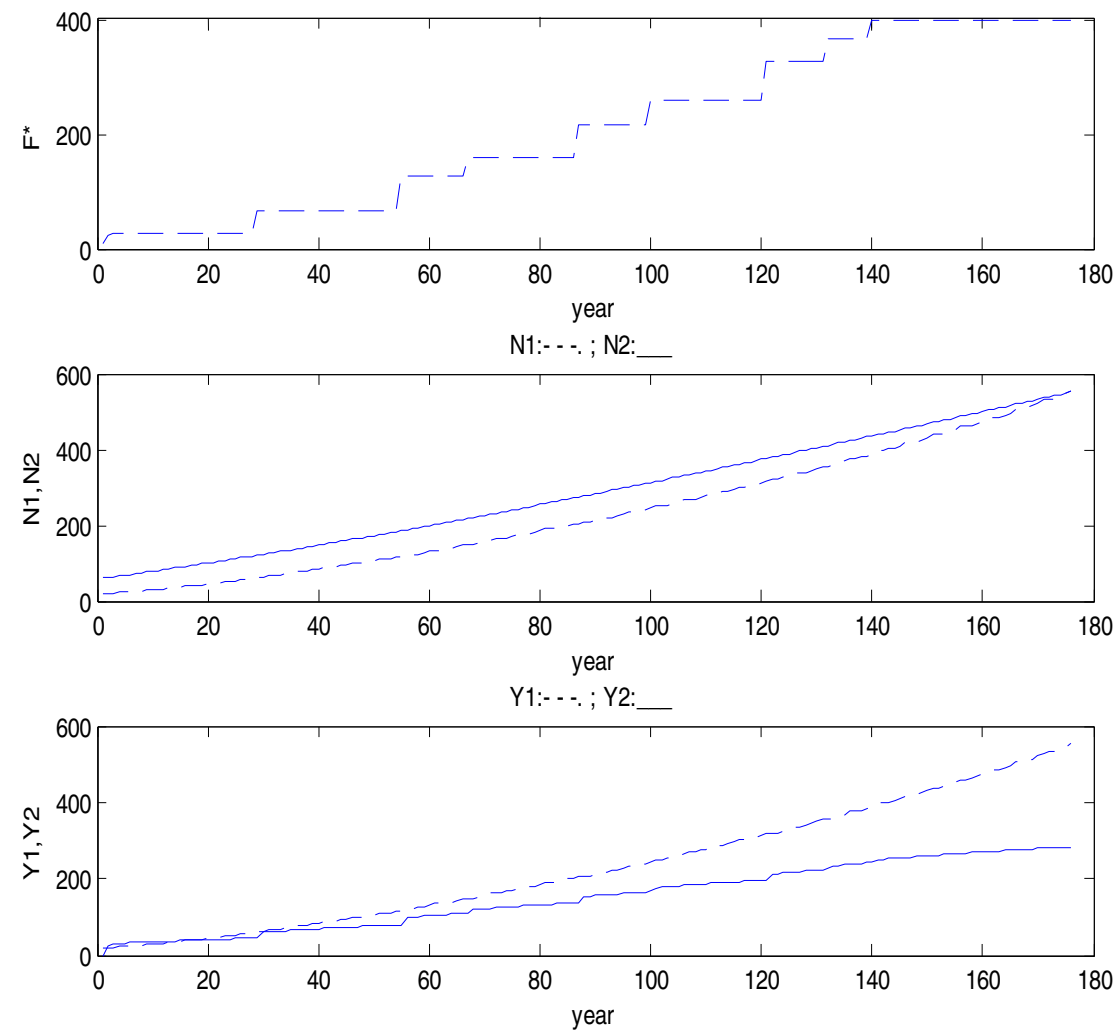

Appendix 3. Simulations for the temporal solution (based on 784,000 data points generated by the initial values $\left\{k^{1}, k^{2}, N^{1}, N^{2}, F\right\}=\{10,50,20$, $60,10\}$; and the parameter ranges: $\left\{\alpha_{1}, \alpha_{2}\right\} \in[0.2,0.5] ;\left\{s_{1}, s_{2}\right\} \in[0.1,0.7] ;\left\{b_{1}, b_{2}\right\} \in[0.1,0.7] ;$ and $\theta \in[0.1,0.9]$, where the increments are taken as 0.1 )

Fig. A3.1 Diversion of informal institutions $\left(N^{1} / N^{2}\right)$ and optimal F.

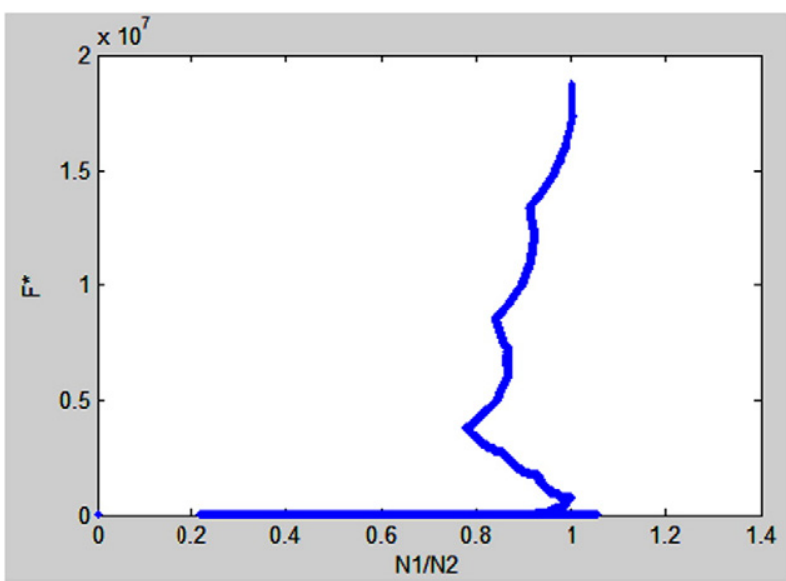


Fig. A3.2 Plots of welfare (vertical axis) against $F^{*}$ and $\left(N^{1} / N^{2}\right)$.

a) $\quad F^{*}$ on the horizontal axis

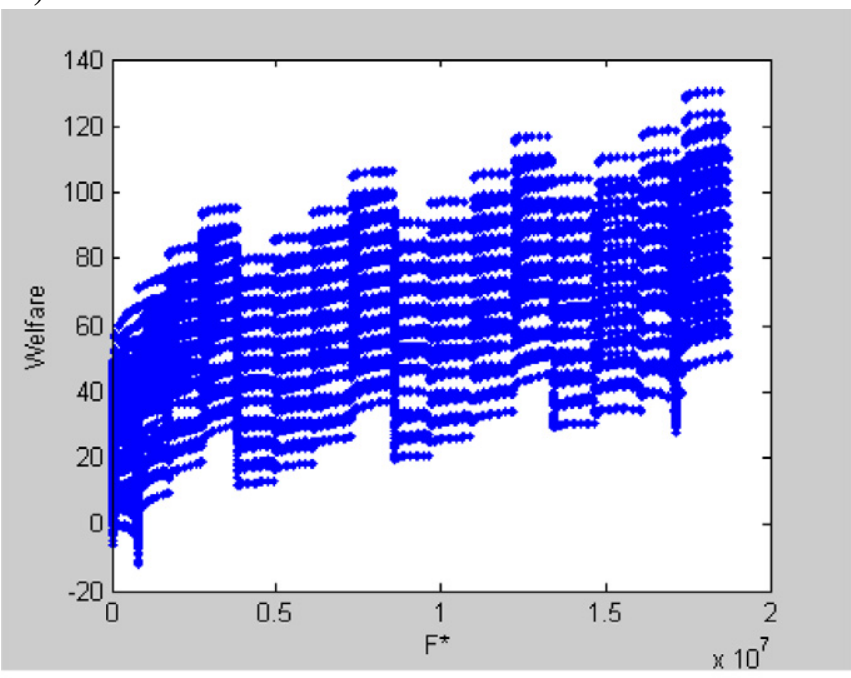

b) $\quad\left(N^{l} / N^{2}\right)$ on the horizontal axis

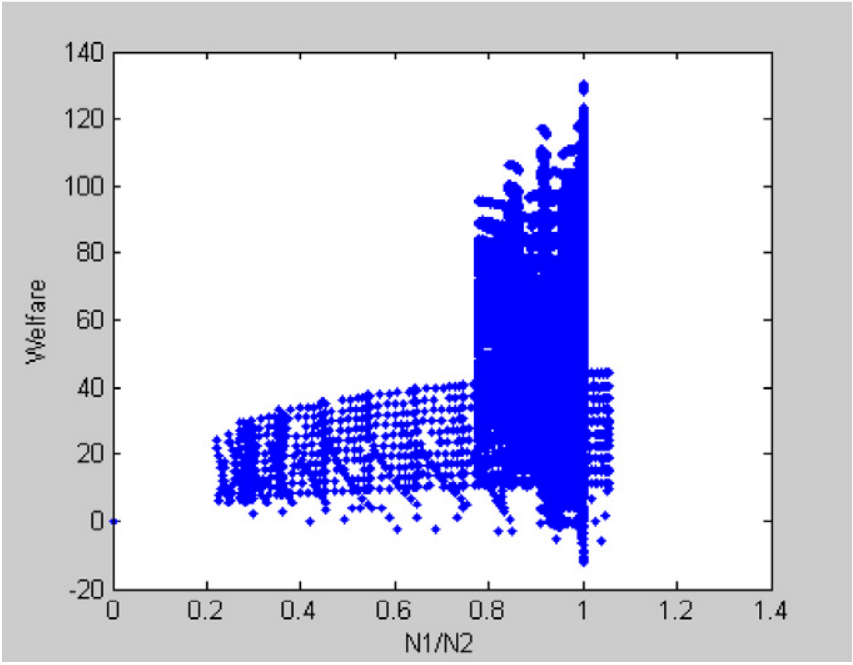

Fig. A3.3 Diversion of informal institutions $\left(N^{1} / N^{2}\right)$ and the sensitivity of $\mathrm{F}^{*}$ to $\gamma_{2}$.

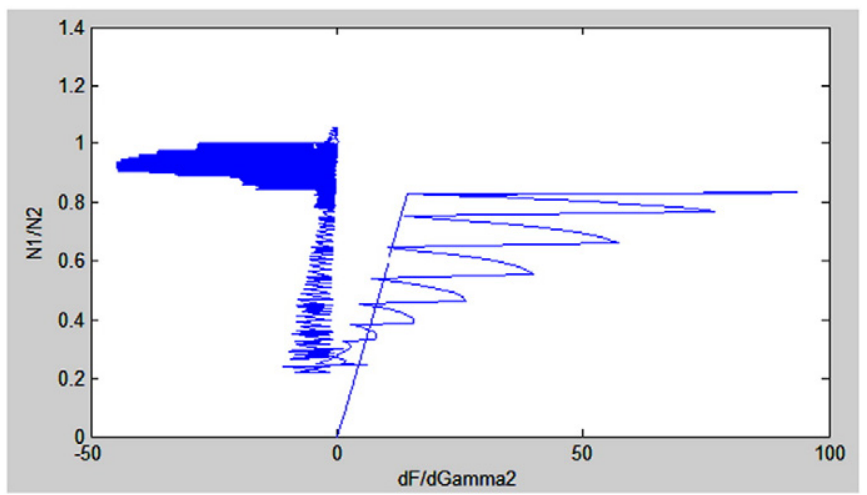




\section{References}

Acemoglu, D., 2006. A simple model of inefficient institutions. Scand. J. Econ. 108, 15-546. Acemoglu, D., Robinson, J.A., 2000. Political losers as a barrier to economic development Am. Econ. Rev. 90, 126-130.

Acemoglu, D., Robinson, J.A., 2012. Why Nations Fail. Crown Publishers, New York.

Aoki, M., 2007. Endogenizing institutions and institutional changes. J. Inst. Econ. 3, 1-31.

Arthur, W., 1988. Self-reinforcing mechanisms in economics. In: Anderson, P., OW.K, Pines, D. (Eds.), The Economy as an Evolving Complex System. Addison-Wesley.

Baumgartner, F., Jones, B.D., 1993. Agendas and Instability in American Politics. University of Chicago Press, Chicago.

Bellettini, G., Ottaviano, G.I.P., 2005. Special interests and technological change. Rev. Econ. Stud. 72, 43-56.

Boettke, P.J., Coyne, C.J., Leeson, P.T., 2008. Institutional stickiness and the new development economics. Am. J. Econ. Soc. 67, 331-358.

Cukierman, A., Webb, S., Neyapti, B., 1992. Measuring the independence of central bank and its policy outcomes. World Bank Econ. Rev. 6, 353-397.

Cukierman, A., Miller, G., Neyapti, B., 2002. Central bank reform, liberalization and inflation in transition economies: an international perspective. J. Monet. Econ. 49, 237-264.

Danielson, P., Ahmad, R., Bornik, Z., Dowlatabadi, H., Levy, E., 2009. Deep, cheap and improvable: dynamic democratic norms and ethics of biotechnology. J. Philos. Res. 32, $315-326$.

Desierto, D.A., 2005. The co-evolution of institutions and technology. Cambridge Working Papers in Economics No. 0558. Faculty of Economics, University of Cambridge, U.K.

Easterly, W., Ritzen, J., Woolcock, M., 2006. Cultural cohesion, institutions and growth. Econ. Polit. 18, 103-120.

Eldredge, N., Gould, S., 1972. Punctuated equilibria: an alternative to phyletic gradualism. In: Schopf, T.J. (Ed.), Models in Paleobiology. Freeman, Cooper \& Co, San Francisco, pp. 82-115.

Granville, B., Leonard, C.S., 2010. Do Informal institutions matter for technological change in Russia? The impact of communist norms and conventions, 1998-2004. World Dev. 38, 155-169.

Grossman, G., Helpman, E., 2001. Special Interest Politics. MIT Press, Cambridge, MA

Hall, R., Jones, 1999. Why do some countries produce so much more output per worker than others? Q. J. Econ. 114, 83-116.
Holcombe, R.G., Boudreaux, J.C., 2013. Institutional quality and the tenure of autocrats. Public Choice 156, 406-421.

Horowitz, D., 1985. Ethnic Groups in Conflict. University of California Press.

Kane, E.J., 1988. Interaction of financial and regulatory Innovation. Am. Econ. Rev. 78, 328-334.

Kuran, T., 2004. Why the middle east is historically underdeveloped: historical mechanisms ofnstitutional stagnation. J. Econ. Perspect. 18, 71-90.

Levi, M., 1988. Of Rule And Revenue. University of California Press, Berkeley.

Marshall, M.G., Jaggers, K., Gurr, T.R., 2011. Polity IV Project. Center for Systemic Peace, University of Maryland, College Park.

Mathers, R.L., Williamson, C.R., 2011. Cultural context: explaining the productivity of capitalism. Kyklos 64, 231-252.

Montalvo, J.G., Reynal-Querol, M., 2005. Ethnic diversity and economic development J. Dev. Econ. 76, 293-323.

Neyapti, B., 2013. Modelling institutional evolution. Econ. Syst. 37, 1-16.

Neyapti, B., Dincer, N., 2005. Measuring the quality of bank regulation and supervision, with an application to transition economies. Econ. Inq. 43, 79-99.

North, D., 1990. Institutions, Institutional Change and Economic Performance. Cambridge University Press, MA

Olson, M., 1982. The Rise And Decline of Nations: Economic Growth, Stagflation, and Social Rigidities. Yale University Press, New Haven.

Roland, G., 2004. Understanding institutional change: fast-moving and slow-moving institutions. J. Comp. Int. Dev. 38, 101-131.

Williamson, O.E., 1985. The Economic Institutions of Capitalism. The Free Press, New York

Williamson, C.R., 2009. Informal institutions rule: institutional arrangements and economic performance. Public Choice 139, 371-387.

Williamson, C.R., Kerekes, C.B., 2011. Securing private property: formal versus informal institutions. J. Law Econ. 54, 537-572.

Williamson, C.R., Mathers, R., 2011. Economic freedom, culture, and growth. Public Choice $148,313-335$

Yao, Y., 2004. Political process and efficient institutional change. J. Inst. Theor. Econ. 160, 439-453. 